\title{
Mein Buch
}

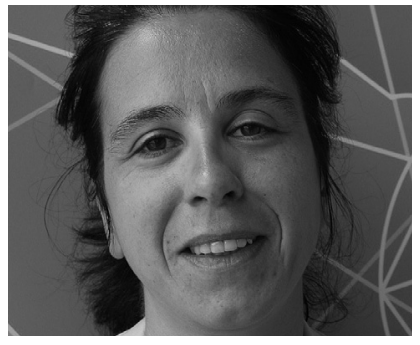

VON PROF: DR: GABRIELE MOOS Moos lehrt Sozialmanagement an der Fachhochschule Koblenz, RheinAhrCampus Remagen, Fachbereich Betriebs- und Sozialwirtschaft. Zudem ist sie 1. Vorsitzende der Deutschen Gesellschaft für Controlling in der Sozialwirtschaft und in NPO e. V. (DGCS) und Mitglied im Beirat der Zeitschrift SOZIALwirtschaft und des Informationsdienstes SOZIALwirtschaft aktuell.

E-Mail

moos@rheinahrcampus.de
Zum Schönsten an Büchern gehört es, dass sie auf ihre stille Weise in das Leben der Leser eingreifen können. Sie nehmen uns mit in Welten, die wir noch nicht kennen, und führen uns zu Einsichten und Erkenntnissen, zu denen wir sonst nie gekommen wären. Es gibt ja viele bedeutsame Bücher, die im Bereich der Sozialwirtschaft zu nennen werden. Für mich ist das erstmals im Jahr 1997 erschiene "Lehrbuch der Sozialwirtschaft " von Ulli Arnold und Bernd Maelicke der Klassiker. Die beiden Herausgeber haben langjährige Erfahrung in der Sozialbranche und auch die zahlreichen Autoren der einzelnen Beiträge sind Praktiker mit Führungsverantwortung in sozialwirtschaftlichen Unternehmen oder Hochschullehrer, Dozenten und Wissenschaftler in einschlägigen Lehrprogrammen.

Das Buch will zu einer systematischen, praxisorientierten und zugleich auch theoretisch fundierten Ausbildung von Führungskräften für sozialwirtschaftliche Organisationen beitragen. Ich nutze dieses Standardlehrbuch regelmäßig, wenn ich Studierenden die komplexe Welt der Sozialwirtschaft erklären will.

Es werden sozialpolitische Entwicklungslinien in Deutschland und Europa aufgezeigt, volkswirtschaftliche Aspekte der Sozialwirtschaft behandelt und theoretische Erklärungsansätze für die Existenz sozialwirtschaftlicher Organisationen geliefert. Das Buch beschreibt zudem sehr übersichtlich den Handlungsbereich sozialer Dienstleistungen in der Bundesrepublik Deutschland mit all seinen vielfältigen Trägerstrukturen und Leistungsbereichen. Positiv ist hervorzuheben, dass zahlreiche betriebswirtschaftliche Fragestellungen behandelt werden, die in sozialwirtschaftlichen Organisationen in spezifischer Weise beantwortet werden müssen. Die Beiträge sind relativ praxisnah, gut lesbar und verständlich abgefasst.
Das »Lehrbuch der Sozialwirtschaft « ist als Grundwerk zur Vermittlung von Basiswissen $\mathrm{zu}$ zentralen thematischen Schwerpunkten der Sozialwirtschaft und des Sozialmanagements hervorragend geeignet. Aus meiner Sicht gibt es kein vergleichbares Standardwerk. Die Erstauflage des Lehrbuchs von 1997 wurde 2003 und 2009 aktualisiert. Dass es das Buch nun schon in der dritten Auflage gibt, mag ein Hinweis sein, dass andere Leser eine ähnliche Einschätzung haben.

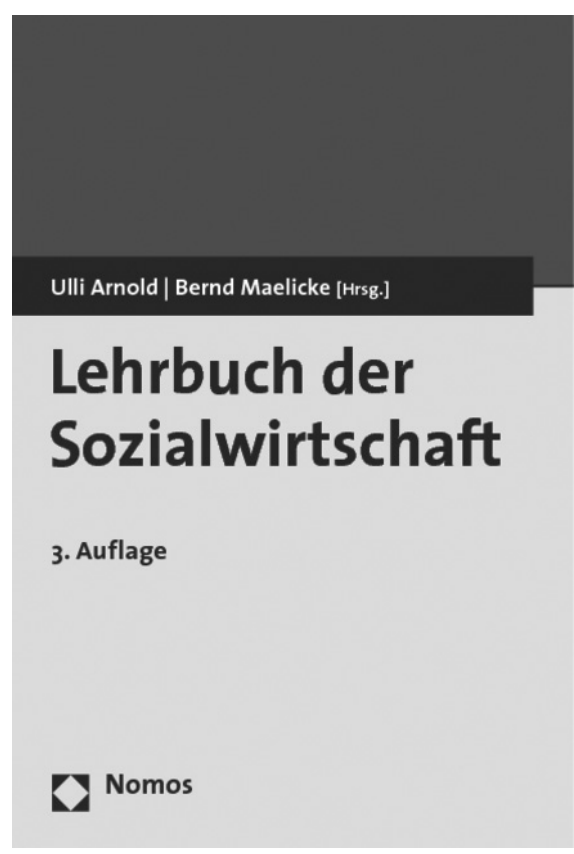

Ulli Arnold, Bernd Maelicke (Hg.): Lehrbuch der Sozialwirtschaft. 3. Auflage. Nomos Verlagsgesellschaft, Baden-Baden 2009. 826 Seiten. 49,- Euro. ISBN 9-783832926809. 